\title{
Modeling research on the extreme hydraulic extension length of horizontal well: impact of formation properties, drilling bit and cutting parameters
}

\author{
$\mathrm{Nu} \mathrm{Lu}{ }^{1} \cdot$ Bo Zhang ${ }^{2}$ (i) $\cdot$ Tao Wang $^{3} \cdot$ Qianming Fu ${ }^{4}$
}

Received: 22 October 2020 / Accepted: 31 January 2021 / Published online: 1 March 2021

(c) The Author(s) 2021

\begin{abstract}
Horizontal well can increase well productivity and improve the economic benefit, which significantly promotes the development of shale gas, tight oil and heavy oil. Moreover, it plays an important role in the development of natural gas hydrate. Horizontal extension ability is one of the key indexes of horizontal well, but it is always impacted by formation properties and well structure. Therefore, a model is established to analyze the impact of formation properties and well structure as comprehensive as possible, which considers not only traditional influencing factors, like formation pressure and drilling bit parameters, but also other key factors, including cutting particle size, wellbore diameter and cross section. Based on the analysis, some advises are proposed for field application. The analysis indicates that horizontal well has stronger extension ability in the formation with low formation pressure and high fracture pressure, but it is still limited by pump pressure. Under-balanced drilling can strength the extension ability in high formation pressure by reducing drilling mud density. The natural fractures in formation should be noted when drilling long horizontal well. The extension length increases and then decreases with the cutting particle size, so cutting particle has optimal size for the horizontal extension length, which can be adjusted by the rate of penetration and rotation speed. The extension length increases first and then decreases with the gap between drilling string and hole. Considering the demand of rock breaking and cutting sweeping around drilling bit, it is not recommended to adjust the drilling bit parameters. Both the cutting bed height and drilling string eccentricity have impact on horizontal extension length by changing minimum cutting-carry pump rate and annular pressure drop. Under different combinations of above two parameters, minimum cutting-carry pump rate and horizontal extension length are determined by different factors and can be divided into three parts, including acceptable cutting bed height, cutting lifting efficiency, pump pressure and total circulation pressure loss and well bottom pressure and formation fracture pressure. The findings of this study can help for better understanding of horizontal well hydraulic extension length and optimization method.
\end{abstract}

Keywords Wellbore cleaning $\cdot$ Horizontal well $\cdot$ Extreme extension $\cdot$ Cutting-carry pump rate $\cdot$ Formation property $\cdot$ Well structure

Bo Zhang

zhangboupc@126.com

1 Research Institute of Petroleum Exploration and Development, PetroChina, Beijing 100083, China

2 Research Institute of Safety and Environment Protection Technology, CNPC, Beijing 102206, China

3 Research Institute of Engineering and Technology, North China Oilfield, PetroChina, Renqiu 062550, China

4 Bazhou Company of Xibu Drilling Engineering Company, CNPC, Korla 841000, China

\begin{tabular}{ll}
\multicolumn{2}{l}{ Abbreviations } \\
$\gamma$ & Intersection angle \\
$\beta$ & Intersection angle \\
$\mu$ & Viscosity \\
$\rho$ & Density \\
$\theta$ & Well inclination angle \\
$A$ & Area \\
$C$ & Coefficient \\
$d$ & Diameter \\
$E$ & Dimensionless eccentricity \\
$e$ & Eccentricity \\
$f$ & Friction coefficient \\
$H$ & Dimensionless cutting bed height \\
$h$ & Cutting bed height
\end{tabular}

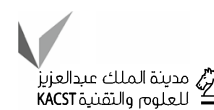




$\begin{array}{ll}h_{\mathrm{v}} & \text { Vertical Depth } \\ k & \text { Drilling fluid consistency index } \\ k_{\mathrm{s}} & \text { Lifting efficiency } \\ L & \text { Length } \\ N & \text { Rotate speed } \\ n & \text { Drilling fluid flow behavior index } \\ p & \text { Pressure } \\ Q & \text { Pump rate } \\ R & \text { Rate of penetration } \\ \operatorname{Re} & \text { Reynolds Number } \\ r & \text { Radius } \\ v & \text { Velocity } \\ \frac{\mathrm{d} p}{\mathrm{~d} L} & \text { Pressure drop }\end{array}$

\section{Introduction}

Unconventional oil and gas have significantly changed the world energy supply market, like shale/tight gas and oil (Al-Fatlawi 2018; Wang et al. 2016a, b; Yang et al. 2019; Zhang et al. 2017), coal bed methane (Al-Jubori et al 2009; Talapatra et al. 2020), heavy oil (Temizel et al. 2018; Ghalenavi et al. 2020), geothermal energy (Austin Anderson \& Behnaz Rezaie 2019; Sui et al. 2018) and even gas hydrate (Li et al. 2020; Lu et al. 2018; Sadeq et al. 2020). Also, current low oil and gas price demand higher production efficiency to reduce cost. In these two aspects, horizontal well is one of the key technologies in order to increase the well productivity (Al-Fatlawi et al. 2019; Alzahabi \& Soliman 2018; Olabode et al. 2020; Ma et al. 2020). For the horizontal extension length, mechanical and hydraulic are two restricted factors ( $\mathrm{Li}$ et al. 2016a). Mechanical factor requires the torque of drilling rig overcomes the drilling string friction torque while the drilling pipe needs to prevent buckle or self-lock. Many related technologies are developed to solve the mechanical limitation, like advanced drilling equipment, low friction drilling fluid and friction reduce tool (Barton et al. 2011; Dong et al. 2015; Wang et al. 2016a, b).

At the same time, a lot work has been done to study the hydraulic factors. As shown in Fig. 1, mathematical models were established based on different engineering background, like, drilling mud window (Li and Gao 2019), shale gas well (Li et al. 2016c), gas drilling (Jiang 2014), deep formation (Xu et al. 2012) and offshore well (Li et al. 2019). All the available researches comply with the principle that the well bottom pressure should be lower than formation fracture pressure and higher than formation pressure. Part of the models took hole cleaning into account while some did not. Some influencing factors were also analyzed, including drilling mud properties, pump pressure, annular pressure drop and rate of penetration. However, to get clear understanding of the extreme hydraulic extension length, it is still necessary to comprehensively analyze the impact of key influencing factors. Therefore, further research is also needed. Among the influencing factors, formation properties and well structure cannot be ignored. To be as comprehensive as possible, the analysis in this paper considers not only traditional influencing factors, like formation pressure or fracture pressure and drilling bit parameters, but also other important factors, including cutting particle size, wellbore diameter and cross section, hoping to provide some advises for field application.

Therefore, this paper is devoted to analyze the impact of formation properties and well structure on the extreme
Fig. 1 Sketch map of extreme hydraulic extension length of horizontal well

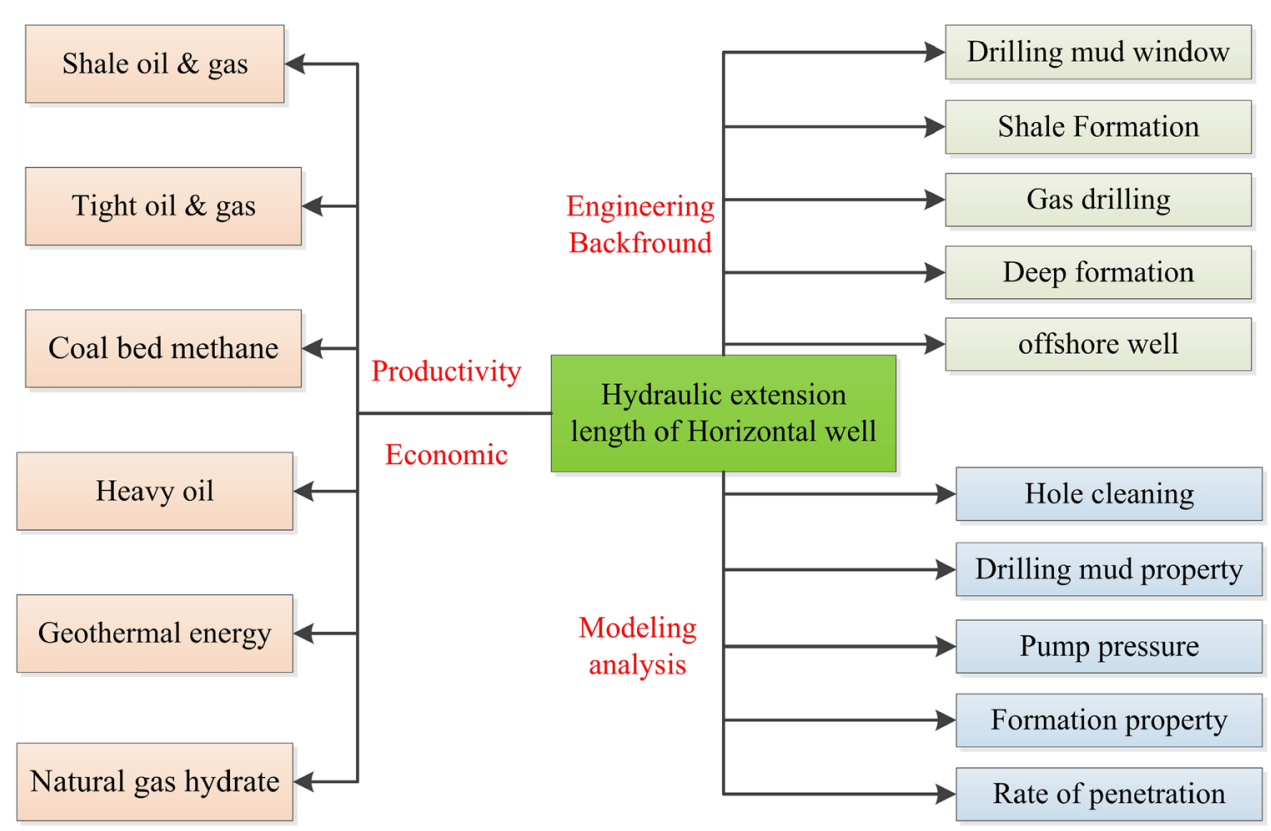


hydraulic extension length of horizontal well. First, the basic principle is proposed to establish the mathematical model, which is defined by minimum cutting-carry pump rate, bottom hole pressure, pump pressure, drilling fluid circulation pressure loss and formation pressure. Then, the calculation methods are provided to obtain the parameters used in the mathematical model. Finally, the sensitivity of influencing factors is evaluated and some advises are proposed to support field operation, including formation pressure and fracture pressure, cutting particle size, wellbore diameter, drilling bit parameter and well cross section.

\section{Mathematical model}

Generally, hydraulic parameters should satisfy two requirements: hole cleaning and pressure balance. For hole cleaning, cuttings are carried by drilling fluid to avoid cutting accumulation in wellbore. So, the drilling fluid pump rate should not be lower than minimum pump rate to carry cuttings. Otherwise, height of cutting bed will increase (Zhang et al. 2020), leading to drilling string stuck, increase in friction and circulation pressure loss. For pressure balance, wellbore bottom pressure should be higher than formation pressure and collapse pressure. While bottom pressure should be lower than formation fracture pressure, in order to keep wellbore stability and prevent gas kick or drilling fluid leakage. Moreover, pump pressure should be higher than the circulation pressure loss of drilling fluid. Assuming there is no natural fracture in the formation and it is overbalanced drilling, the above requirements can be expressed as Eq. (1):
$\left\{\begin{array}{l}Q \geq Q_{\mathrm{cm}} \\ \max \left(p_{\mathrm{p}}, p_{\mathrm{c}}\right) \leq p_{\mathrm{bh}} \leq p_{\mathrm{f}} \\ \Delta p_{\mathrm{L}} \leq p_{\mathrm{pw}}\end{array}\right.$

where $p_{\mathrm{p}}$-formation pressure, $\mathrm{MPa} ; Q$-drilling fluid pump rate, $\mathrm{L} / \mathrm{s} ; Q_{\mathrm{cm}}$-minimum pump rate to carry cuttings, $\mathrm{L} / \mathrm{s} ; p_{\mathrm{f}}$-formation fracture pressure, $\mathrm{MPa} ; p_{\mathrm{c}}$-formation collapse pressure, $\mathrm{MPa}, p_{\mathrm{bh}}$-wellbore bottom pressure, $\mathrm{MPa}$; $\Delta p_{\mathrm{L}}$-total circulation pressure loss, $\mathrm{MPa} ; p_{\mathrm{pw}}$-pump pressure, MPa.

In Eq. (1), both wellbore bottom pressure and total circulation pressure loss are related to drilling fluid pump rate and horizontal extension length. As shown in Fig. 2, minimum cutting-carry pump rate is determined by acceptable cutting bed height and required lifting efficiency. And then, two values of horizontal extension length can be obtained from Eq. (1). The hole cleaning meets the requirement when the drilling fluid pump rate is $Q_{\mathrm{cm}}$. and then the extreme hydraulic extension length can be defined as Eq. (2). Finally, this model can be used to analyze the imapct of formation properties and well structure, thus providing support and guidance based on the result and analysis.

$L_{\mathrm{m}}=\min \left(L_{\mathrm{bh}}, L_{\mathrm{cl}}\right) \mid Q=Q_{\mathrm{cm}}$

where $L_{\mathrm{m}}$-extreme hydraulic extension length of horizontal well, $m ; L_{\mathrm{bh}}$-horizontal extension length restricted by bottomhole pressure, $\mathrm{m} ; L_{\mathrm{cl}}$-horizontal extension length restricted by total circulation pressure loss, $m$.
Fig.2 Flowchart of the modeling analysis

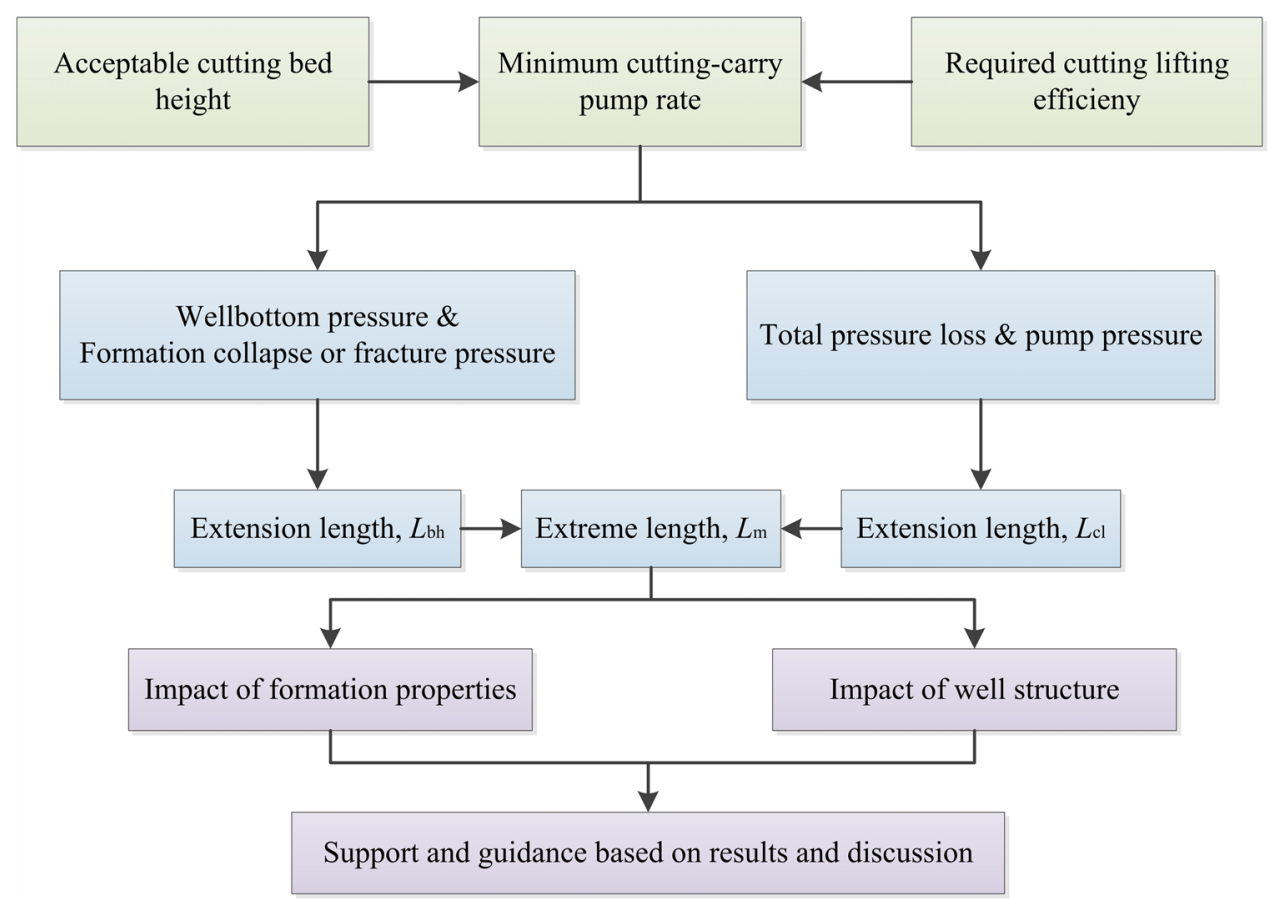




\section{Minimum pump rate to carry cuttings}

Horizontal well has vertical and horizontal section. Moreover, wellbore diameter changes along the depth (Zhang et al. 2015), so different drilling fluid pump rates are required to carry cuttings in different well sections. To assure the hole cleaning, the largest pump rate is selected as the minimum pump rate to carry cuttings, as expressed by Eq. (3) and (4):

$Q_{c m}=\max \left(Q_{\mathrm{c} 1}, Q_{\mathrm{c} 2} \ldots \ldots Q_{\mathrm{c} i}\right)$

$Q_{\mathrm{c}}=10^{-3} v_{\mathrm{ac}} \frac{\pi\left(D^{2}-d_{\mathrm{o}}^{2}\right)}{4}$

where $\mathrm{Q}_{\mathrm{c} i}$-minimum pump rate to carry cuttings at $i^{\text {th }}$ well section, $\mathrm{L} / \mathrm{s} ; v_{\mathrm{ac}}$-minimum annular velocity to carry cuttings, $\mathrm{m} / \mathrm{s} ; D$-wellbore diameter, $\mathrm{mm} ; d_{\mathrm{o}}$-drilling string diameter, $\mathrm{mm}$.

\section{Well bottom pressure and circulation pressure loss}

Drilling fluid flows inside drilling string and drilling bit, then flows back to ground through horizontal annulus and vertical annulus. According to U-pipe principle, well bottom pressure can be divided into four parts. First part is generated by hydrostatic fluid column. Second part is additional pressure caused by the velocity and density differences between cuttings and drilling fluid in the vertical well section (Liu et al. 2004). Third part is the annular pressure loss in horizontal well section. This part should consider the impact of cutting bed and drilling string eccentricity on the circulation pressure drop. The forth part is the annular pressure loss in other well section. Also, the well diameter may change, so the pressure drop per unit is different, which means annular pressure drop consist of several parts. Combining the above parts, well bottom pressure can be expressed by Eq. (5):

$$
\begin{aligned}
p_{\mathrm{bh}} & =p_{\mathrm{h}}+\Delta p_{\mathrm{cs}}+p_{\mathrm{ac}}+p_{\mathrm{vc}} \\
& =0.0098 \rho_{\mathrm{f}} h_{\mathrm{v}}+\Delta p_{\mathrm{cs}}+C_{\mathrm{b}} \sum_{i=1}^{n} \frac{\mathrm{d} p_{\mathrm{a} i}}{\mathrm{~d} L} L_{i}+\sum_{j=1}^{m} \frac{\mathrm{d} p_{\mathrm{a} j}}{\mathrm{~d} L} L_{j}
\end{aligned}
$$

where $p_{\mathrm{h}}$-pressure generated by hydrostatic fluid column, $\mathrm{MPa} ; \Delta p_{\mathrm{cs}}$-additional pressure, $\mathrm{MPa} ; p_{\mathrm{ac}}$-pressure loss in horizontal well section, $\mathrm{MPa} ; p_{\mathrm{vc}}$-pressure loss in other well section, $\mathrm{MPa} ; \rho_{\mathrm{f}}$-density of drilling fluid, $\mathrm{g} / \mathrm{cm}^{3} ; C_{\mathrm{b}}$ coefficient of horizontal annular circulation pressure drop, dimensionless; $\frac{\mathrm{d} p_{\mathrm{a} i}}{\mathrm{~d} L}$-annular pressure drop of $j$ th vertical and inclined well section, $\mathrm{MPa} / \mathrm{m} ; L_{i}$-length of $i$ th horizontal well section, $\mathrm{m} ; \frac{\mathrm{d} p_{a j}}{\mathrm{~d} L}$-annular pressure drop of $j$ th vertical well section, $\mathrm{MPa} / \mathrm{m} ; L_{j}$-length of $j$ th vertical well section, $\mathrm{m} ; h_{\mathrm{v}}$-vertical depth of wellbore, $m$.

Total circulation pressure drop consists of annular pressure loss, pressure loss inside drilling pipe, ground manifold pressure loss and drilling bit pressure loss, as expressed by Eq. (6):

$\Delta p L=\Delta p g+\Delta p b+\left(p_{\mathrm{bh}}-p_{\mathrm{h}}-\Delta p_{\mathrm{cs}}\right)+\Delta p \mathrm{~d}$

where $\Delta p_{\mathrm{g}}$-ground manifold pressure loss, $\mathrm{MPa} ; \Delta p_{\mathrm{b}}$-drilling bit pressure loss, $\mathrm{MPa} ; \Delta p_{\mathrm{d}}$-pressure loss inside drilling pipe, MPa.

Pressure loss of ground manifold can be obtained by ground test. Drilling bit pressure loss is expressed by Eq. (7):

$\Delta p_{\mathrm{b}}=\frac{\rho_{\mathrm{f}} Q^{2}}{2 C^{2} A_{\mathrm{b}}^{2}}$

where $C$-drilling Bit flow rate coefficient, dimensionless; $A_{\mathrm{b}}$-drilling bit flow area, $\mathrm{cm}^{2}$.

\section{Sensitivity analysis}

A well is selected to analyze the influencing factors (Zhang et al., 2018). The basic calculation parameters are as shown in Table.1. In this study, the nominal pressure drilling pump is $25.5 \mathrm{MPa}$ and nominal capacity is $44.98 \mathrm{~L} / \mathrm{s}$.
Table 1 Basic calculation parameters

\begin{tabular}{llll}
\hline Parameters & Value & Parameters & Value \\
\hline Acceptable cutting bed height & $5 \%$ & Vartical depth & $2395 \mathrm{~m}$ \\
Drilling string diameter & $101.6 \mathrm{~mm}$ & Formation pressure & $1.113 \mathrm{~g} / \mathrm{cm}^{3}$ \\
Drilling fluid density & $1.31 \mathrm{~g} / \mathrm{cm}^{3}$ & Formaiton collapse pressure & $1.015 \mathrm{~g} / \mathrm{cm}^{3}$ \\
Drilling string rotation speed & $50 \mathrm{r} / \mathrm{min}$ & Formaiton fracture pressure & $2.284 \mathrm{~g} / \mathrm{cm}^{3}$ \\
Drilling string eccentricity & 0.71 & Cutting density & $2.315 \mathrm{~g} / \mathrm{cm}^{3}$ \\
Drilling fluid consistency index & $0.6715 \mathrm{~Pa} \cdot \mathrm{s}^{\mathrm{n}}$ & Rate of penetration & $4.17 \mathrm{~m} / \mathrm{h}$ \\
Flow behavior index & 0.5243 & Drilling bit flow rate coefficient & 0.965 \\
Yield value/plastic viscosity & $0.6551 \mathrm{~Pa} / \mathrm{cP}$ & Drilling bit flow area & $3.6 \mathrm{~cm}$ \\
Casing diameter & $177.8 \mathrm{~mm}$ & Drilling bit diameter & $152.4 \mathrm{~mm}$ \\
Casing setting depth & $2610 \mathrm{~m}$ & Kickoff point & $2090 \mathrm{~m}$ \\
\hline
\end{tabular}




\section{Impact of formation properties}

\section{Formation pressure}

As shown in Fig. 3, the extreme hydraulic horizontal extension length decreases as the formation pressure increases. Meanwhile, the minimum pump rate decreases. This is because the drilling fluid density also increases in order to balance the formation pressure. As a result, the hydrostatic column pressure increases. For example, the hydrostatic column pressure increases from 29.34 MPa to 38.32 MPa when the drilling fluid density increases from $1.25 \mathrm{~g} / \mathrm{cm}^{3}$ to $1.6 \mathrm{~g} /$ $\mathrm{cm}^{3}$. According to Eq. (10), this is obviously adverse to the extension of horizontal extension length. Heavier drilling fluid makes the well bottom pressure higher. This means the annular pressure drop should be lower in order to prevent well bottom pressure exceeding formation fracture pressure. As a result, the extension length should be reduced when the formation fracture pressure and well vertical depth do not change. In the field practice, high-pressure formation should be sealed to get longer horizontal extension ability.

\section{Formation fracture pressure}

As shown in Fig. 4, extreme hydraulic horizontal extension length increases as the formation fracture pressure increases. Therefore, the horizontal extension length would be reduced in the easy-leak formation. Moreover, the existence of natural fracture is also adverse for the extension of horizontal well, because natural fracture is easier for drilling fluid leakage even when the well bottom pressure is not higher than formation fracture pressure. Meanwhile, extreme horizontal extension length increases first and then becomes unchanged when the pump pressure is lower. As the horizontal length extends, the total circulation pressure loss also increases and finally exceeds the pump pressure. And then, the limited

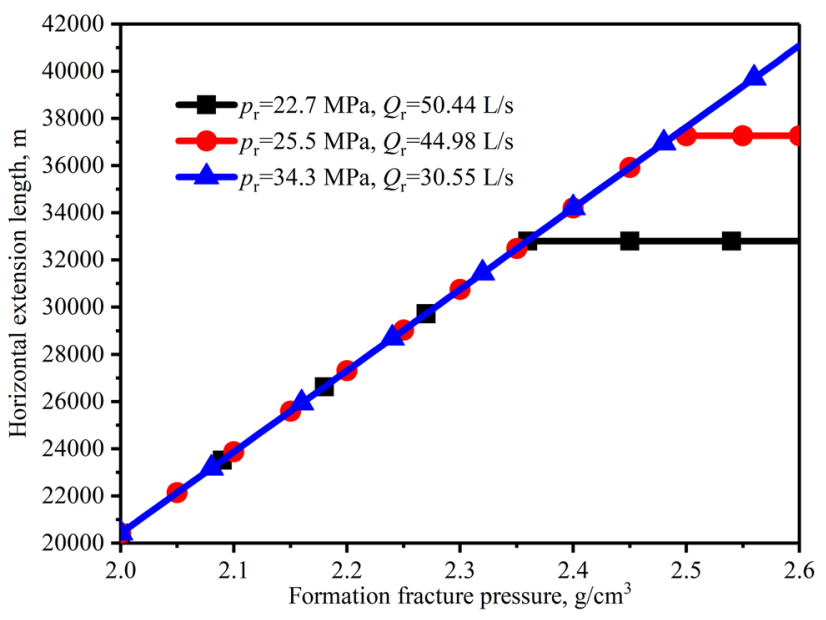

Fig. 4 Impact of formation fracture pressure

pump pressure restricts the extension of horizontal well, so the extension length does not change again.

\section{Impact of drilling bit parameters}

\section{Drilling bit diameter}

As shown in Fig. 5, there is a peal value in the curve of extreme horizontal extension length. It increases first and then decreases as wellbore diameter increases. This is because extreme horizontal extension length is determined by well bottom pressure and formation fracture pressure determines before the peak value. Larger wellbore diameter brings lower annular pressure loss, so the horizontal extension length increases. After the peak value, the determinant factors become pump pressure and total circulation pressure drop. The decrease in annular pressure drop is not adequate to compensate the impact of higher minimum pump rate.

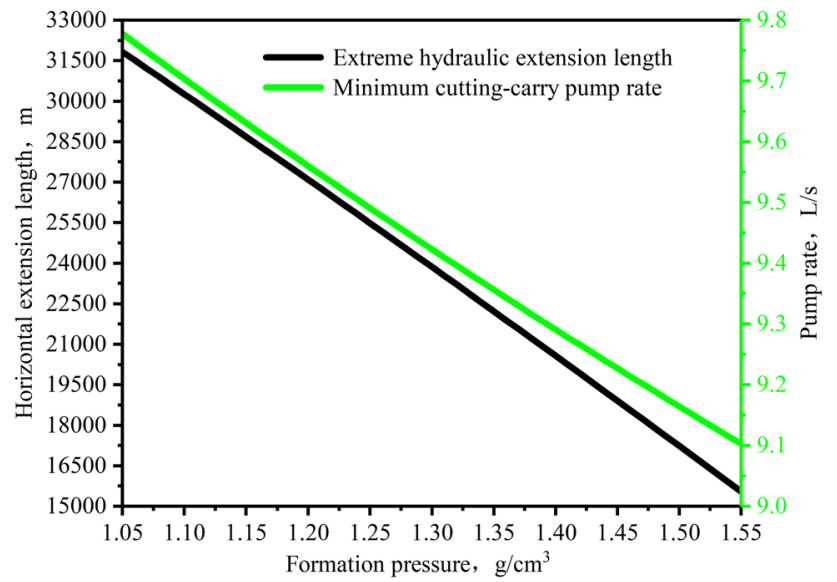

Fig. 3 Impact of formation pressure

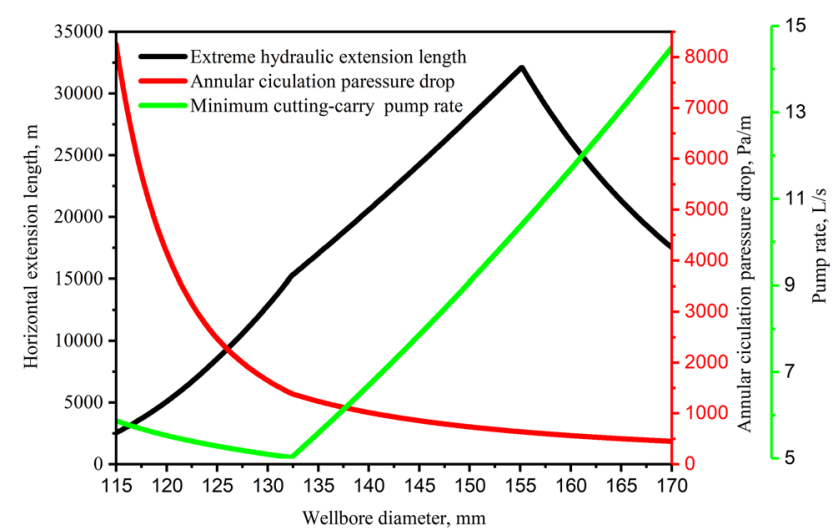

Fig. 5 Impact of wellbore diameter 
This indicates the suitable combination of drilling string and wellbore can help to extend horizontal well section.

\section{Flow rate coefficient and flow area}

As shown in Fig. 6, extreme hydraulic horizontal extension length increases as the flow rate coefficient and flow area increase. However, the difference between maximum and minimum values in Fig. 7 is only $4.60 \%$. According to Eqs. (6) and (7), drilling bit flow rate coefficient and flow area have impact on the extreme hydraulic horizontal extension length when the total circulation pressure and formation fracture pressure are the determinant factors. Considering the drilling bit parameters are important for rock breaking and cutting sweeping around drilling bit (Cao et al. 2019), it is not recommended to adjust the drilling bit parameters.

\section{Impact of cuttings}

\section{Cutting particle size}

As shown in Fig. 7, extreme hydraulic horizontal extension length increases first and then decreases as the cutting particle size increases. Meanwhile, the trend of minimum pump rate is opposite. This can be explained by the impact of cutting particle size on hole cleaning. In the horizontal well section, cutting particle is moved by drag forces, lifting forces and forces generated by fluid pressure gradients(Walker and Li 2000), which increases as the cutting particle size increases. So, smaller drilling fluid pump rate is needed to carry the cuttings. However, for vertical well section, the gravity of cutting particle increase as the size increases, so larger drilling pump rate is needed to carry the cuttings. As a result, the minimum cutting-carry pump rate is determined first by cutting bed height and then by cutting

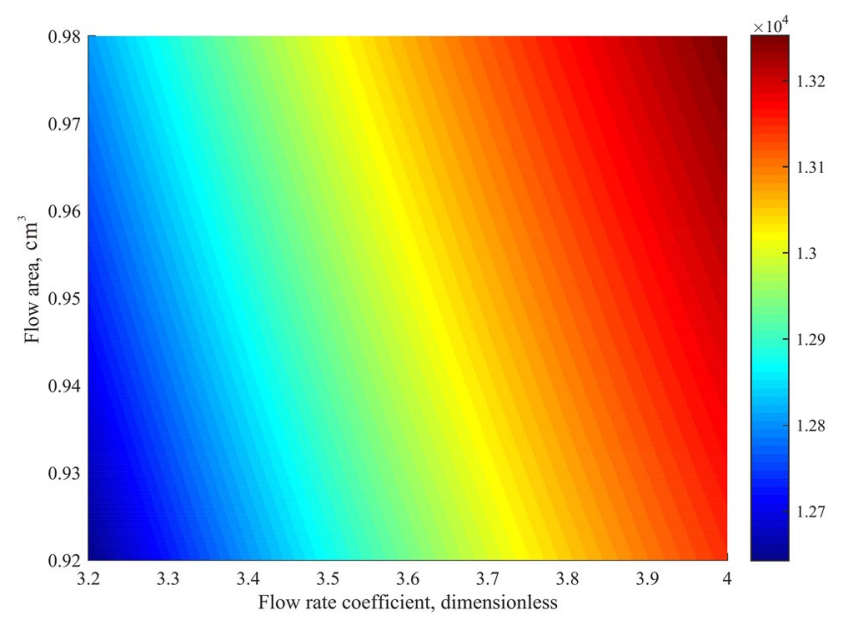

Fig. 6 Impact of drilling bit parameters

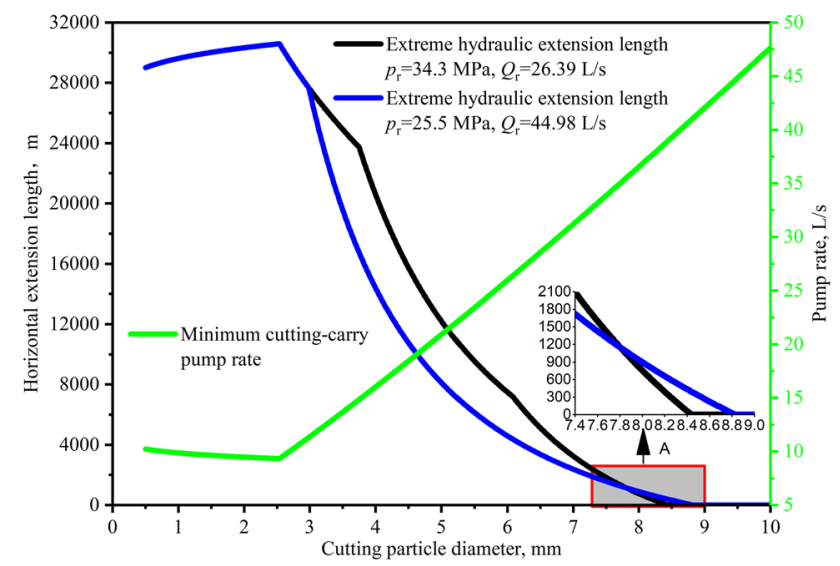

Fig. 7 Impact of cutting particle size

lifting efficiency as cutting size increases. The cutting size is related to the rate of penetration and rotation speed, so horizontal well section can extension longer by optimizing the rate of penetration and rotation speed.

\section{Cutting bed height}

Together with drilling string eccentricity, cutting bed height determines the cross section geometry of horizontal well. As shown in Fig. 8, it can be seen that extreme hydraulic horizontal extension length increases first and then decreases as the acceptable cutting bed height increases. As for the drilling string eccentricity, Fig. 8 can be divided into part A and part B. Extreme horizontal extension length increases in part A, but it increases first and then decreases in part B as the drilling string eccentricity increases. This indicates that the determinant factors are different under different combinations of cutting bed height and drilling string eccentricity.

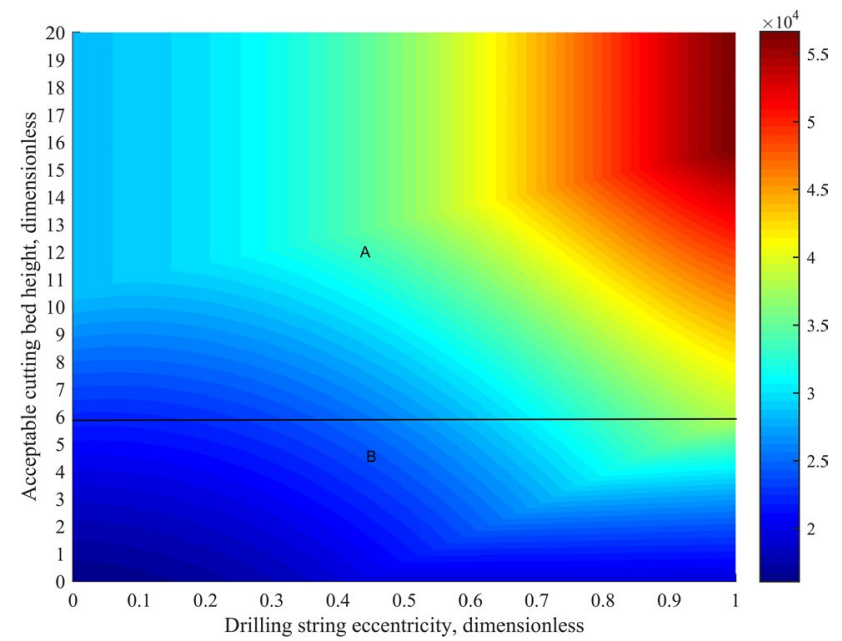

Fig. 8 Impact of cross section geometry of horizontal well 
Table 2 and Fig. 9 provide the determinant factors. There are three combinations of the determinant factors. In the green area and blue area, the cutting-carry pump rate is determined by acceptable cutting bed height. In yellow area, the determinant factor is cutting lifting efficiency. Moreover, the factors to determine extreme hydraulic horizontal extension length also changes. In green area, the determinant factors are pump pressure and total circulation pressure loss. In blue area and yellow area, the factors change to well bottom pressure and formation fracture pressure.

\section{Summary and Conclusions}

To analyze the impact of formation properties and well structures, a model is established by taking the hole cleaning, drilling pump condition and formation limitation into account. By this model, some new factors are analyzed, including cutting particle size, wellbore diameter and cross section. Based on the analysis, new understanding is obtained to provide support for the field application of horizontal well. The conclusions are as follows:

- The horizontal well has stronger hydraulic extension ability in formation with high fracture pressure, but the pump pressure is still a restricted factor. Due to the heavier drilling fluid density caused by high formation pressure, extreme hydraulic horizontal extension length decreases. The horizontal extension length would be reduced by easy-leak formation or natural fracture. When the total circulation loss exceeds pump pressure, the extreme extension length is not impacted by formation fracture pressure. It is recommended to seal the formation with high-pressure or adopt under-balanced drilling.

- Extreme horizontal extension length increases first and then decreases as the cutting particle size increases. As cutting particle size increases, the minimum cuttingcarry pump rate of horizontal well section decreases, while the pump rate of vertical well increases. Therefore, the minimum cutting-carry pump rate is determined first by cutting bed height and then by cutting lifting efficiency, so there is an optimal cutting particle size for the extension of horizontal well. The cutting particle size can be optimized by the rate of penetration and rotation speed.

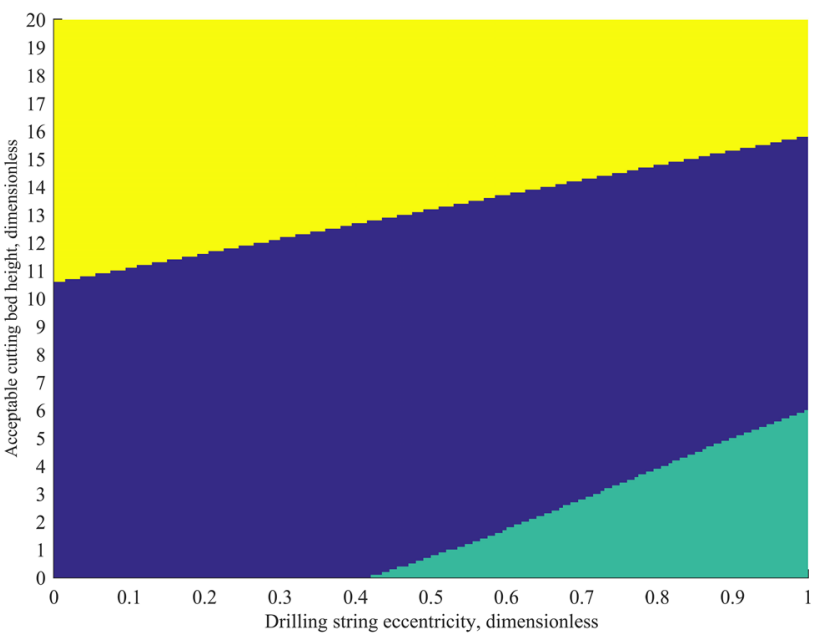

Fig. 9 Colorful areas corresponding to combinations of the determinant factors

- Extreme horizontal extension length increases first and then decreases as the drilling string diameter increase, so suitable combination of drilling string and wellbore can help to extend horizontal well extension length. The impact of drilling bit parameters is not so remarkable. Considering the demand of rock breaking and cutting sweeping around drilling bit, it is not recommended to adjust the drilling bit parameters.

- The determinant factors of cutting-carry pump rate and extreme hydraulic horizontal extension length are different under different combinations of cutting bed height and drilling string eccentricity. Cutting bed height and drilling string eccentricity impact horizontal extension length by changing minimum cutting-carry pump rate and annular pressure drop. Under different combinations of above two parameters, minimum cutting-carry pump rate and horizontal extension length are determined by different factors and can be divided into three parts, including acceptable cutting bed height, cutting lifting efficiency, pump pressure and total circulation pressure loss, and well bottom pressure and formation fracture pressure

- Further research is still necessary to improve this work. First, natural fracture is ignored, which would certainly change the formation fracture pressure, especially carbonate formation. Second, some of the equations in the model

Table 2 Combinations of the determinant factors

\begin{tabular}{lll}
\hline Area in Fig. 9 & Factor to determine cutting-carry pump rate & Factors to determine extreme hydraulic horizontal dispacemet \\
\hline Green area & Acceptable cutting bed height & Pump pressure and total circulation pressure loss \\
Blue area & Acceptable cutting bed height & Well bottom pressure and formation fracture pressure \\
Yellow area & Cutting lifting efficiency & Well bottom pressure and formation fracture pressure \\
\hline
\end{tabular}


are empirical. Although empirical equations have been verified by experimental tests, it may also have unknown disadvantages in some situations. Third, some limitations are worthy to continue studying. Other types of drilling method should be considered, such as gas drilling and managed pressure drilling. The extension ability should take the downhole motor or other downhole tools into account, such as cutting-carry tool and rotary steering.

\section{Appendix 1}

\section{Calculation of minimum drilling fluid velocity}

Drilling fluid velocity is used to calculate minimum cuttingcarry pump rate. As shown in Fig. 10, cutting lifting efficiency is used to evaluate hole cleaning in vertical well section. Usually, cutting lifting efficiency should not be lower than 0.5 . Cutting lifting efficiency is determined by drilling fluid annular velocity, as expressed by Eq. (8):

$$
\left\{\begin{array}{l}
k_{\mathrm{s}}=1-\frac{v_{\mathrm{s}}}{v_{\mathrm{a}}} \\
v_{\mathrm{s}}=0.707 d_{s}\left(\rho_{s}-\rho_{\mathrm{f}}\right)^{\frac{2}{3}} / \rho_{\mathrm{f}}^{\frac{1}{3}} \cdot \mu_{\mathrm{e}}^{\frac{1}{3}}
\end{array}\right.
$$

where $k_{\mathrm{s}}$-cutting lifting efficiency, dimensionless; $v_{\mathrm{s}}$-cuttings slip velocity, $\mathrm{m} / \mathrm{s}$.

As shown in Fig. 11, hole cleaning of horizontal section is evaluated by cutting bed height, so the minimum cuttingcarry pump rate of horizontal well section is determined by acceptable cutting be height. The relationship between cutting bed height and drilling fluid annular velocity can be expressed by Eq. 9 (Wang et al. 2014). This equation is obtained based on two assumptions. First, annular flow is solid-liquid two-phase. Second, cutting particle is hypothesized as spheroidal. Through Eq. 9, minimum annular velocity to carry cuttings of horizontal section can be obtained after the acceptable cutting bed height is known. viscosity of drilling fluid, $\mathrm{Pa} \cdot \mathrm{s} ; H_{\mathrm{c}}$-cutting bed height, mm; $\mathrm{H}_{\mathrm{a}}$-acceptable cutting bed height, dimensionless.

The related parameters are provided by Eq. $10 \sim 12$, including effective viscosity of drilling fluid (Erge et al. 2015), drilling string eccentricity (Guan et al. 2016) and cutting diameter (Zhou et al. 2008):

$\mu_{\mathrm{e}}=k\left(\frac{D-d_{\mathrm{o}}}{12000 v_{\mathrm{a}}}\right)^{1-n}\left(\frac{2 n+1}{3 n}\right)^{n}$

$E=\frac{2 e}{D-d_{\mathrm{o}}}$

$d_{\mathrm{s}}=\frac{R_{\mathrm{P}}}{0.6 N}$

where $e$-eccentricity, mm; $k$-drilling fluid consistency index, $\mathrm{Pa} \cdot \mathrm{s}^{\mathrm{n}} ; n$-drilling fluid flow behavior index, dimensionless.

\section{Appendix 2}

\section{Additional pressure caused by cuttings}

Additional pressure includes two parts. One is caused by density difference and the other is caused by the friction between cuttings and drilling fluid, as expressed by Eq. (13) and (14) (Liu et al. 2005):

$\Delta p_{\mathrm{cs}}=h_{\mathrm{v}} \Delta \rho_{\mathrm{sf}}\left(0.0098+\frac{2 f_{\mathrm{s}}\left(v_{\mathrm{a}}-v_{\mathrm{s}}\right)^{2}}{D-d_{\mathrm{o}}}\right)$

$f_{\mathrm{cb}}= \begin{cases}\frac{64}{\operatorname{Re}}, & \operatorname{Re} \leq 2300 \\ \frac{0.316}{\operatorname{Re}^{0.25}} & , \operatorname{Re}>2300\end{cases}$

where $\Delta \rho_{\text {sf }}$-drilling fluid density change caused by the

$$
\left\{\begin{aligned}
H= & 6.489 \rho_{\mathrm{f}}^{-2.45} \rho_{\mathrm{s}}^{-0.51}\left(-v_{\mathrm{a}}^{1.567}+0.16 v_{\mathrm{a}}^{0.57}+1.62 v_{\mathrm{a}}^{-0.433}\right)\left(-0.003 \theta^{2}+0.3744 \theta-1.27\right) \\
& \times(1+0.5 E)(1+N)^{-0.185}\left[10 d_{\mathrm{s}} /\left(D-d_{\mathrm{o}}\right)\right]^{-0.15} R_{\mathrm{P}}^{0.276}\left(\mu_{\mathrm{e}}^{2}+0.711 \mu_{\mathrm{e}}+0.0692\right) \\
H= & \frac{H_{\mathrm{C}}}{D-d_{\mathrm{o}}} \leq H_{\mathrm{a}}
\end{aligned}\right.
$$

where $H$-relative cutting bed height, $\% ; \rho_{\mathrm{s}}$-cutting density, $\mathrm{g} / \mathrm{cm}^{3} ; v_{\mathrm{a}}$-annular velocity of drilling fluid, $\mathrm{m} / \mathrm{s} ; \theta$-well inclination angle, ${ }^{\circ} ; E$-drilling string eccentricity, dimensionless; $N$-drilling string rotate speed, $\mathrm{r} / \mathrm{min} ; d_{\mathrm{s}}$-cutting diameter, $\mathrm{cm} ; R_{\mathrm{P}}$-rate of penetration, $\mathrm{m} / \mathrm{s} ; \mu_{\mathrm{e}}$-effective mixture of cuttings, $\mathrm{g} / \mathrm{cm}^{3} ; f_{\mathrm{s}}$-friction coefficient between cuttings and drilling fluid, dimensionless; re-drilling fluid Reynolds number, dimensionless. 
Fig. 10 Sketch map of vertical well section

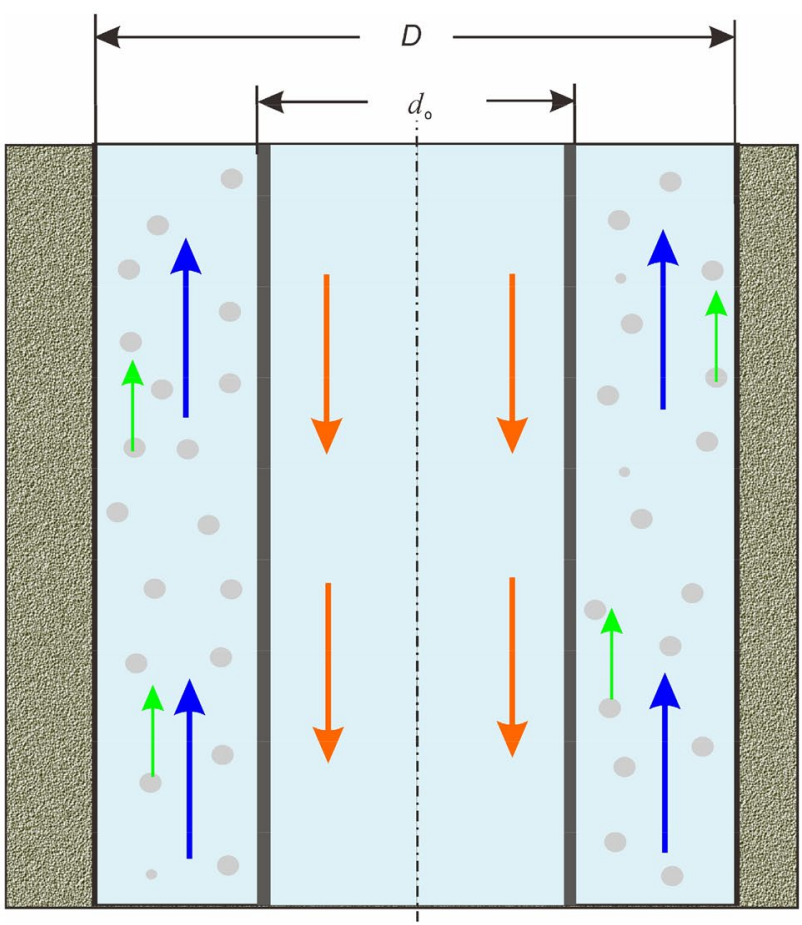

Drilling fluid

Flow direction of drilling fluid inside drilling string

Alow direction of drilling fluid in annulus

Cutting particle velocity

Cutting particle

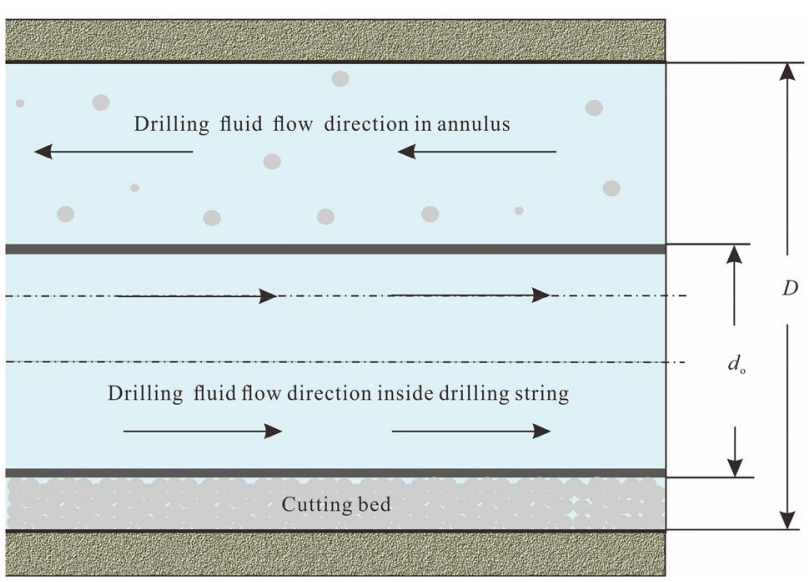

Fig. 11 Sketch map of horizontal well section

Density change in Eq. 13 is determined by the cutting properties, rate of penetration and drilling fluid pump rate (Liu et al. 2005), as shown in Eq. 15:

$\Delta \rho_{\mathrm{sf}}=\frac{\pi R_{\mathrm{p}} D_{\mathrm{h}}^{3}\left(\rho_{\mathrm{s}}-\rho\right)}{\pi R_{\mathrm{p}} D_{\mathrm{h}}^{3}+4000 \times 3600 Q}$

Reynolds number can be calculated by Eq. (16) (Erge et al. 2015):

$$
\operatorname{Re}=10^{3-3 n} \frac{12^{1-n} \rho_{\mathrm{f}}(D-d o)^{n} v_{\mathrm{a}}^{2-n}(3 n)^{n}}{k(2 n+1)^{n}}
$$

\section{Appendix 3}

\section{Coefficient of annular circulation pressure drop}

As shown in Fig. 11, horizontal section has two typical characteristics. Firstly, drilling string is eccentric due to gravity. Secondly, drilling string is buried by cutting bed. As a result, coefficient of horizontal annular circulation pressure drop is expressed by Eq. 17:

$C_{\mathrm{b}}=C_{\mathrm{ec}} \times C_{\mathrm{cb}}$

where $C_{\mathrm{ec}}$-coefficient caused by eccentric drilling string, dimensionless; $C_{\mathrm{cb}}$-coefficient caused by cutting bed, dimensionless.

The coefficient caused by eccentric drilling string was from experimental data (Haciislamoglu and Cartalos, 1994; Haciislamoglu and Langlinais 1990). It was provided this equation by analyzing eccentric flow data in terms of eccentricity, pipe diameter ratioand flow behavior index, as expressed by Eq. 18: 
$C_{\mathrm{ec}}=\left\{\begin{array}{l}1-0.072 \frac{E}{n}\left(\frac{d_{\mathrm{o}}}{D}\right)^{0.8454}-1.5 E^{2} \sqrt{n}\left(\frac{d_{\mathrm{o}}}{D}\right)^{0.1852}+0.96 E^{3} \sqrt{n}\left(\frac{d_{\mathrm{o}}}{D}\right)^{0.2527}, \text { laminar flow } \\ 1-0.048 \frac{E}{n}\left(\frac{d_{\mathrm{o}}}{D}\right)^{0.8454}-\frac{2}{3} E^{2} \sqrt{n}\left(\frac{d_{\mathrm{o}}}{D}\right)^{0.1852}+0.285 E^{3} \sqrt{n}\left(\frac{d_{\mathrm{o}}}{D}\right)^{0.2527}, \text { turbulent flow }\end{array}\right.$

Likewise, impact of annular circulation pressure drop is also obtained and proved by experimen data (Chen et al. 2016). In the experiment, the drilling string is rotary, and drilling fluid is liquid (Wang et al. 1996). This coefficient is related to cutting bed height, cutting density and drilling fluid velocity, as expressed by Eq. 19:

$C_{c b}=\frac{0.026 H}{f_{c b}}\left[\frac{1000 v_{a}^{2}}{g\left(D-d_{0}\right)} \frac{\rho_{f}}{\rho_{s}-\rho_{f}}\right]^{-1.25}+1+0.00582 H$

\section{Appendix 4}

\section{Pressure drop considering wellbore cross section}

Without considering the impact of cutting bed and eccentric drilling string, the annular pressure drop can be calculated by Fanning-Darcy formula, as expressed by Eq. 19:

$\frac{\mathrm{d} p_{\mathrm{a}}}{\mathrm{d} L}=\frac{200 f \rho_{\mathrm{f}} Q^{2}}{A^{2}\left(D-d_{\mathrm{o}}\right)}$

where $f$-friction coefficient of drilling fluid, dimensionless; $A$-flow open area, $\mathrm{cm}^{2}$.

The friction coefficient of drilling fluid is related to flow regimes and shape of flow area. For tube laminar flow, it can be expressed by Eq. 20 (Li et al. 2016b):

$f=\frac{16}{\operatorname{Re}}$

For annular laminar flow, it can be expressure by Eq. 21 (Kelessidis et al. 2011):

$f=\frac{24}{\operatorname{Re}}$

For turbulent flow, it can be calculate by revised Pelatius resistance formula (Hetsroni 1990), as expressed by Eq. 22:

$f=\left\{\begin{array}{l}\frac{a}{4 \operatorname{Re}^{b}} \\ a=0.3104 n^{0.105} \\ b=0.2495 n^{-0.217}\end{array}\right.$
Flow regimes of drilling fluid can be judged by critical Reynolds number as expressed by Eq. 23:

$\operatorname{Re}_{c}=3470-1370 n$

It can be known from Eq. 19 that flow open area is also one of the factors to impact annular circulation pressure drop. Flow open area can be divided into three types. As shown in Fig. 12, the eccentric drilling string is fully inside annular flow open area in type $a$, which means $\mathrm{e}+\mathrm{r}_{\mathrm{o}} \leq \mathrm{r}-\mathrm{h}$. The flow area is the area difference of wellbore, drilling string and cutting bed. According to the area formula of round and triangle, the flow area can be expressed as Eq. (24):

$A=10^{-4} \pi\left(r^{2}-r_{\mathrm{o}}^{2}\right)-10^{-4}\left[\beta r^{2}-(r-h) \times r \sin \beta\right]$

According to the definition of dimensionless cutting bed height and the inverse trigonometric function, $h$ and $\beta$ can be expressed by Eq. 25:

$h=H \times D$

$\beta=a \cos ((r-h) / r)$

where $r$-wellbore radius, $\mathrm{mm} ; r_{\mathrm{o}}$-drilling string outer radius, $\mathrm{mm} ; h$-cutting bed real height, $\mathrm{mm} ; \beta$-intersection angle, ${ }^{\circ}$.

As shown in Fig. 13, part of the drilling string is buried in the cutting bed in type $\mathrm{b}$, which means $r-h<e+r_{\mathrm{o}} \&$ $h \leq r+r_{\mathrm{o}}-e$. At this time, the flow area can be calculated by four steps. First step is to calculate area of wellbore. Second step is to calculate the area of drilling string above

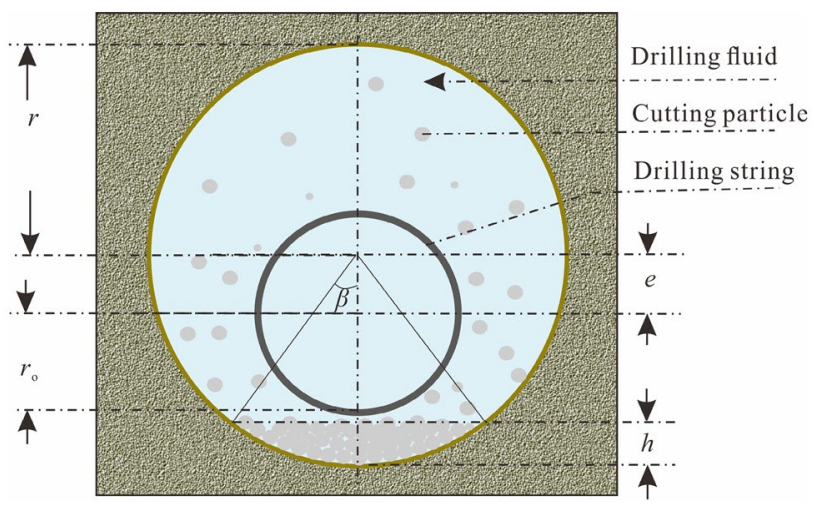

Fig. 12 Flow area of first type a 


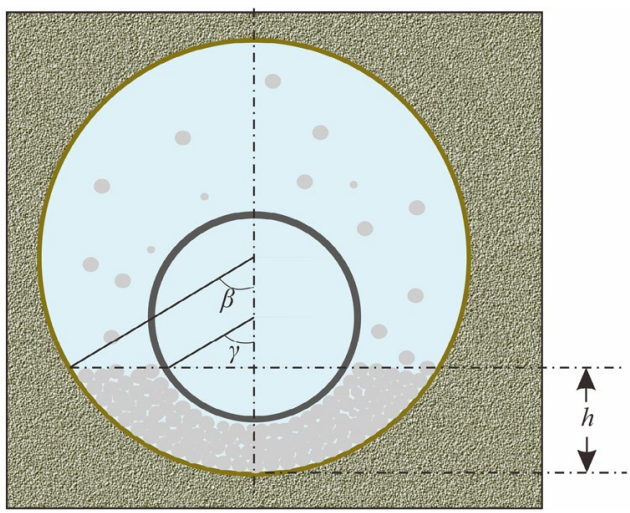

Fig. 13 Flow area of first type $b$

the cutting bed. Third step is to calculate the area of cutting bed and drilling string buried inside the cutting bed. Finally, the flow area is obtained by making difference of the areas obtained from above three steps, as expressed by Eq. 25 after combining like terms:

$A=10^{-4}\left[r^{2}(\pi-\beta)+r(r-h) \sin \beta-r_{\mathrm{o}}^{2}(\pi-\gamma)-r_{\mathrm{o}}(r-h-e) \sin \gamma\right]$

Angle $\gamma$ can be expressed by Eq. 26 according to inverse trigonometric function:

$\gamma=a \cos \left((r-h-e) / r_{\mathrm{o}}\right)$

where $\gamma$-intersection angle, ${ }^{\circ}$.

As shown in Fig. 14, the whole drilling string is buried in the cutting bed in type $\mathrm{c}$, which means $h>r+r_{o}-e$. At this time, the flow area can be calculated by four steps. First step is to calculate the area of the wellbore. Second step is to calculate the area under the cutting bed and drilling string in the lower half of wellbore, which is round solitary. Third step is to calculate the cutting bed and drilling string in the upper half of wellbore, which is triangle. Finally, the flow area is obtained by making difference of the areas obtained from above three steps, as expressed by Eq. 26 after combining like terms:

$A=10^{-4}\left[r^{2}(\pi-\beta) \pm r(r-h) \sin \beta\right]$

Acknowledgements This research is supported by China Postdoctoral Science Foundation (2019M662467) and Excellent Postdoctoral Fund of Xinjiang Province (RSSQ00065690).

Funding China Postdoctoral Science Foundation (2019M662467) and Excellent Postdoctoral Fund of Xinjiang Province, China (RSSQ00065690).

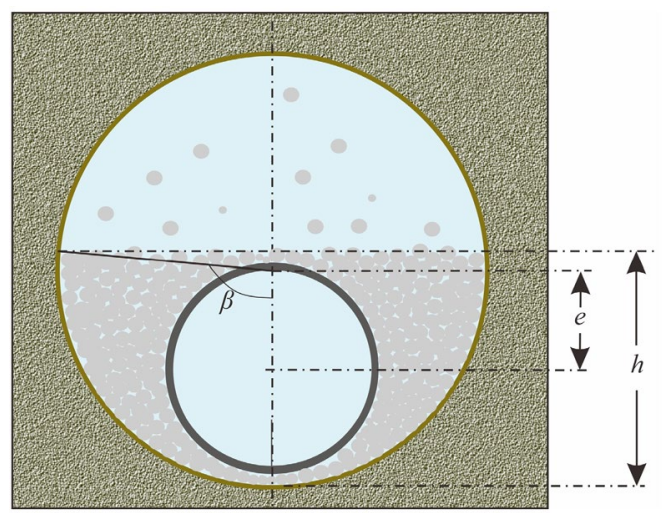

Fig. 14 Flow area of first type c

\section{Compliance with ethical standards}

Conflict of interest On behalf of all the co-authors, the corresponding author states that there is no conflict of interest.

Open Access This article is licensed under a Creative Commons Attribution 4.0 International License, which permits use, sharing, adaptation, distribution and reproduction in any medium or format, as long as you give appropriate credit to the original author(s) and the source, provide a link to the Creative Commons licence, and indicate if changes were made. The images or other third party material in this article are included in the article's Creative Commons licence, unless indicated otherwise in a credit line to the material. If material is not included in the article's Creative Commons licence and your intended use is not permitted by statutory regulation or exceeds the permitted use, you will need to obtain permission directly from the copyright holder. To view a copy of this licence, visit http://creativecommons.org/licenses/by/4.0/.

\section{References}

Al-Fatlawi OF (2018) Numerical simulation for the reserve estimation and production optimization from tight gas reservoirs. Doctoral dissertation, Curtin University of Technology

Al-Fatlawi O, Hossain M, Patel N, Akim K (2019) Evaluation of the potentials for adapting the multistage hydraulic fracturing technology in tight carbonate reservoir. Paper presented at the SPE Middle East Oil and Gas Show and Conference, Manama, Bahrain. SPE 194733

Al-Jubori A, Johnston S, Boyer C, Lambert SW, Bustos OA, Pashin JC, Wray A (2009) Coalbed methane: clean energy for the world. Oilfield Review 21(2):4-13

Alzahabi A, Soliman MY (2018) Optimization of Hydraulic Fracture Stages and Sequencing in Unconventional Formations. CRC Press

Anderson A, Rezaie B (2019) Geothermal technology: trends and potential role in a sustainable future. Appl Energy 248:18-34

Barton SP, Baez F, Alali A (2011) Drilling Performance improvements in gas shale plays using a novel drilling agitator device. Paper 
presented at the North American unconventional gas conference and exhibition, The Woodlands, Texas, USA. SPE 144416.

Cao T, Yu K, Chen X, Gao D, Zhu H, Luo Y (2019) Numerical and experimental investigation on the feasibility of horizontal drilling with a new type of jet mill bit. ASME J Energy Resour Technol 141(9):093101

Chen, X., Gao, D. (2016) Mega-Extended-Reach Drilling to Deepwater Target: What is the Well's Maximum Allowable Measured Depth While Drilling? Paper presented at the Abu Dhabi International Petroleum Exhibition \& Conference, Abu Dhabi, UAE. SPE 183025

Dong X, Wang L, Yang X, Lin Y, Xue Y (2015) Effect of ester based lubricant smjh-1 on the lubricity properties of water based drilling fluid. J Petrol Sci Eng 135:161-167

Erge O, Ozbayoglu EM, Miska SZ, Yu M, Takach N, Saasen A (2015) Laminar to turbulent transition of yield power law fluids in annuli. J Petrol Sci Eng 128:128-139

Ghalenavi H, Norouzi-Apourvari S, Schaffie M, Ranjbar M (2020) Significant effect of compositional grading on SAGD performance in a fractured carbonate heavy oil reservoi. J Petrol Explor Prod Technol 10:903-910

Guan Z, Liu Y, Liu Y, Xu Y (2016) Hole cleaning optimization of horizontal wells with the multi-dimensional ant colony algorithm. J Nat Gas Sci Eng 28:347-355

Haciislamoglu M, Cartalos U (1994) Practical pressure loss predictions in realistic annular geometries. Paper presented at the SPE annual technical conference and exhibition, New Orleans, Louisiana. SPE 28304.

Haciislamoglu M, Langlinais J (1990) Non-Newtonian flow in eccentric annuli. J Energy Resour Technol 112(3):163-169

Hetsroni G (1990) Handbook of hydraulic resistance. Int J Multiphas Flow 16(1):169-169

Hossain MM, Rahman MK, Rahman SS (2000) Application of HDR stimulation technology to develop tight gas reservoirs. Paper presented at SPE Asia Pacific Oil and gas conference and exhibition. SPE 64484.

Jiang J (2014) Horizontal extension ability of gas drilling. Southwest petroleum university.

Kelessidis VC, Dalamarinis P, Maglione R (2011) Experimental study and predictions of pressure losses of fluids modeled as HerschelBulkley in concentric and eccentric annuli in laminar, transitional and turbulent flows. J Petrol Sci Eng 77:305-312

Li J, Tan T, Zhang H, Deng Q, Wang H, Cai Z, Liu K (2019) Study on the open-hole extended-reach limit model analysis for offshore reelwell drilling method. 53rd U.S. rock mechanics/geomechanics symposium, American Rock Mechanics Association, New York City, USA

Li S, Li S, Pang W (2020) Description of gas hydrate using digital core technology. ASME J Energy Resour Technol 142(6):062901

Lu N, Hou J, Liu Y, Barrufet MA, Ji Y, Xia Z (2018) Stage analysis and production evaluation for class iii gas hydrate deposit by depressurization. Energy 165:501-511

Li X, Gao D (2019) Study on mud weight window prediction model and safety additional value of horizontal well in shales considering effects of well's extended-reach limit. J Petrol Sci Eng 173:579-587

Li X, Gao D, Zhou Y, Zhang H (2016a) A model for extended-reach limit analysis in offshore horizontal drilling based on formation fracture pressure. J Petrol Sci Eng 146:400-408

Li X, Gao D, Zhou Y, Zhang H (2016b) Study on open-hole extendedreach limit model analysis for horizontal drilling in shales. J Nat Gas Sci Eng 34:520-533

Liu Y, Zhou Y, Wang G, Zhai H, Shao T (2005) Effect of annular cuttings on negative pressure in under-balanced drilling process. Acta Petro Sin 26(6):96-98
Ma X, Li X, Liang F, Wan Y, Shi Q, Wang Y, Zhang X, Che M, Guo W, Guo W (2020) Dominating factors on well productivity and development strategies optimization in Weiyuan shale gas play, Sichuan Basin. SW China Petrol Explor Develop 47(3):594-602

Olabode O, Isehunwa S, Orodu O, Ake D (2020) Optimizing productivity in oil rims: simulation studies on horizontal well placement under simultaneous oil and gas production. J Petrol Explor Prod Technol online. https://doi.org/10.1007/s13202-020-01018-9

Sadeq D, Al-Fatlawi O, Iglauer S, Lebedev M, Smith C, Ahmed B (2020) Hydrate equilibrium model for gas mixtures containing methane, nitrogen and carbon dioxide. Paper presented at the Offshore Technology Conference, Houston, Texas, USA. OTC 30586

Sui D, Wiktorski E, Røksland MN, Basmoen TA (2018) Review and investigations on geothermal energy extraction from abandoned petroleum wells. J Petrol Explor Prod Technol 9:1135-1147

Talapatra A (2020) A study on the carbon dioxide injection into coal seam aiming at enhancing coal bed methane (ECBM) recovery. J Petrol Explor Prod Technol 10:1965-1981

Temizel C, Canbaz CH, Tran M, Abdelfatah E, Jia B, Putra D, Irani M, Ahmad A (2018) A Comprehensive Review Heavy Oil Reservoirs, Latest Techniques, Discoveries, Technologies and Applications in the Oil and Gas Industry. Paper presented at the SPE International Heavy Oil Conference and Exhibition, Kuwait City, Kuwait. SPE 193646

Walker S, Li J (2000) The Effects of Particle Size, Fluid Rheology and Pipe Eccentricity on Cuttings Transport. Paper presented at the SPE/ICoTA Coiled Tubing Roundtable, Houston, Texas, USA. SPE 60755

Wang H, Liu X, Ding G, Li H (1996) Development of model for pressure drop in annular space of horizontal well. J China Univ Pet Nat Sci Ed 20(2):30-35

Wang H, Ma F, Tong X, Liu Z, Zhang X, Wu Z, Li D, Wang B, Xie Y, Yang L (2016a) Assessment of global unconventional oil and gas resources. Petrol Explor Devel 43(6):925-940

Wang J, Sun B, Li H, Xiang H, Wang Z, Tian A (2014) Simulation analysis of cuttings velocity distribution in extended horizontal well drilling. Chin J Hydrodyn 29(6):739-748

Wang P, Ni H, Wang R, Li Z, Wang Y (2016b) Experimental investigation of the effect of in-plane vibrations on friction for different materials. Tribol Int 99:237-247

Xu K, Xiong J, Chen J, Qin D, Xu H (2012) The evaluation and analysis of hydraulic extensions ability of horizontal section in deep horizontal wells. J Southwest Pet Uni Sci Technol Ed 34(6):101-106

Yang J, Wang X, Peng X, Du Z, Zeng F (2019) Experimental studies on co2 foam performance in the tight cores. J Petrol Sci Eng 175:1136-1149

Zhang B, Guan Z, Hasan AR, Wang Q, Xu Y, Zhang Z (2018) Prediction and analysis of extreme extension length of horizontal well based on hole cleaning degree. Arab J Sci Eng 43(05):2537-2546

Zhang B, Guan Z, Zhang Q (2015) Prediction and analysis on annular pressure of deepwater well in the production stage. Acta Petrolei Sinica 36(8):1012-1017

Zhang F, Wang Y, Wang Y, Miska S, Yu M (2020) Modeling of dynamic cuttings transportation during drilling of oil and gas wells by combining 2D CFD and 1D discretization approach. SPE J 25(03):1220-1240

Zhang Q, Su Y, Zhang M, Wang W (2017) A multi-linear flow model for multistage fractured horizontal wells in shale reservoirs. J Petrol Explor Prod Technol 7:747-758

Zhou B, Liu G, Li J (2008) Research on floating mud cap-bottom hole pressure model. Drill Produ Technol 31(06):4-7

Publisher's Note Springer Nature remains neutral with regard to jurisdictional claims in published maps and institutional affiliations. 